Mo 21 A05

\title{
Spectral Analysis and Correlation of Ambient Seismic Noise. The Case Study of Madonna del Sasso (NW Italy)
}

C. Colombero* (Università di Torino), L. Baillet (Univ. Grenoble Alpes, ISTerre, CNRS), C. Comina (Università di Torino), A. Helmstetter (Univ. Grenoble Alpes, ISTerre, CNRS), D. Jongmans (Univ. Grenoble Alpes, ISTerre, CNRS), E. Larose (Univ. Grenoble Alpes, ISTerre, CNRS), J. Valentin (Univ. Grenoble Alpes, ISTerre, CNRS) \& S. Vinciguerra (Università di Torino)

\section{SUMMARY}

Ambient vibrations recorded on potentially-unstable rock slopes show that the temporal variations in the spectral content and in the correlation of seismic noise can be related to both reversible and irreversible changes within the rock mass. In this work, we analyzed the seismic recordings acquired at the potentiallyunstable granitic cliff of Madonna del Sasso (NW Italy) from October 2013 to November 2014.

The spectral content of noise systematically highlighted clear energy peaks at specific frequencies on the most unstable sector, interpreted as resonant frequencies of the investigated volume. Horizontal ground motion at the fundamental frequency was moreover found to be orthogonal to the main fractures observed at the site and consequently parallel to the potential direction of collapse. Cross-correlation was computed between the recordings of the sensors placed in the prone-to-fall compartment and a stable reference station.

Both the temporal variations of the resonant frequencies and the results of cross-correlation showed seasonal reversible variations related to temperature fluctuations. No irreversible changes, resulting from damage processes within the rock mass, were detected during the monitored period. 


\section{Introduction}

Ambient vibration surveys have been recently applied to potentially-unstable rock slopes, with different geological settings and volumes, showing the capability of spectral analysis of seismic noise to detect both reversible and irreversible modifications within the rock masses.

Literature studies, mostly carried out in the Alpine context (Moore et al. 2011; Burjánek et al., 2012; Bottelin et al., 2013), systematically highlighted clear energetic peaks at specific frequencies on the unstable sectors, which were interpreted as resonant frequencies of the investigated volumes. Horizontal ground motion at the fundamental frequency was moreover found to be orthogonal to the main fractures observed at the sites and consequently parallel to the potential direction of collapse. Each unstable compartment showed seasonal reversible variations of the resonant frequencies related to temperature fluctuations. In some cases, also irreversible variations were detected. Lévy et al. (2010) recorded a significant drop $(>1 \mathrm{~Hz})$ in the lowest resonant frequency two weeks before the effective collapse of a limestone column.

In this framework, seismic noise data from a microseismic monitoring network, recently installed at the potentially-unstable cliff of Madonna del Sasso (VB, NW Italy), are discussed here. The aim of the work was to analyze, throughout spectral analysis and cross-correlation, seismic noise recordings and to eventually identify the characteristic signs of pre-failure in the rock mass.

In this work we focus on the processing methodologies and on the results obtained from seismic noise analysis during the first months of operation of the network.

\section{The test site: Madonna del Sasso (NW Italy)}

The cliff of Madonna del Sasso $\left(45^{\circ} 79^{\prime} \mathrm{N}, 8^{\circ} 37^{\prime} \mathrm{E}\right)$ is located in NW Italy, on the western shore of the Orta Lake. It is a high massive granite outcrop bordered on three sides (N, E and S) by roughly vertical walls, with a height of about $200 \mathrm{~m}$ (Fig. 1a). A preliminary geomechanical characterization (Lancellotta et al., 1991) led to the identification of four main joint sets affecting the site (dip direction/dip): K1 (110/75), K2 (0/80), K3 (150/15) and K4 (50/75). Particularly, a decimetric displacement step is clearly visible on the yard in front of the sanctuary along the main fracture of the $\mathrm{K} 4$ system. On the other hand, the major fracture of the $\mathrm{K} 2$ system is open of more than $30 \mathrm{~cm}$, with a persistence of several meters at depth. These discontinuities (Fig. 1b) tend to isolate the north-western frontal portion of the cliff which increases its instability as a function of the rock joints along the fractures and its foot edge. A volume of about $12,000 \mathrm{~m}^{3}$ has been estimated forming the most unstable sector.
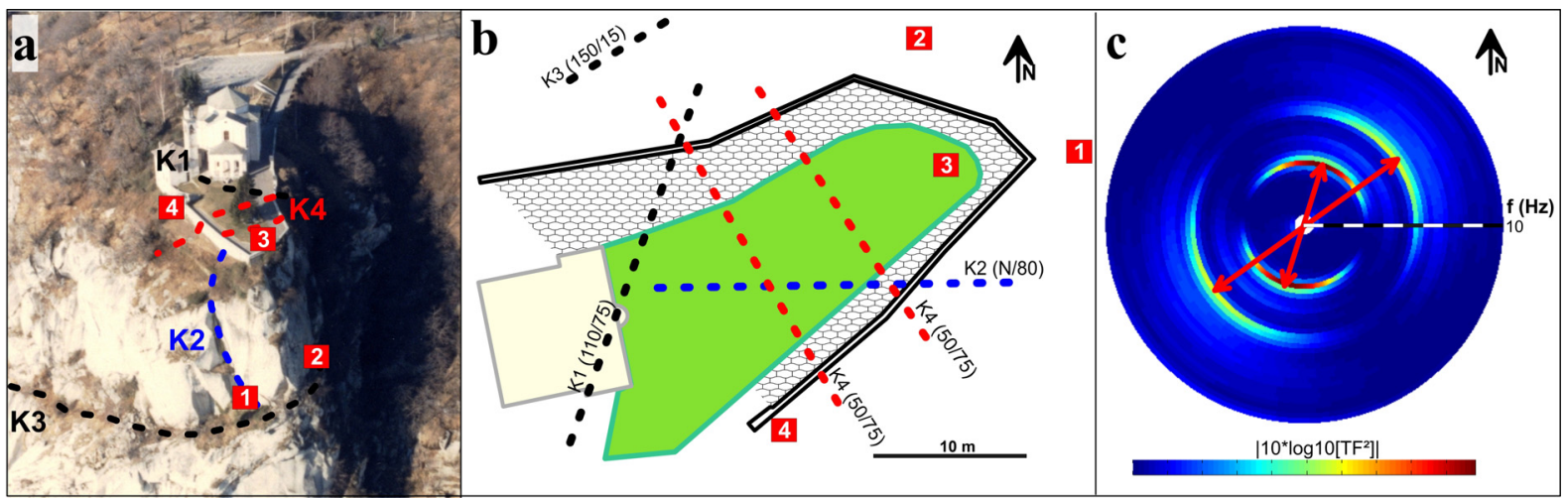

Figure 1 Eastern view (a) and planar scheme (b) of the site with the location of the microseismic stations (red squares) and the traces of the main fractures (dashed lines). Numbers in brackets refer to dip direction and dip of each system. (c) Polar plot of the stacking of night recordings of seismic noise for the horizontal components of ST3. Red arrows highlight the directions of the two main peaks. 
The microseismic network was operating at Madonna del Sasso from the end of October 2013 to August 2014. It consisted of four triaxial geophones $(4.5 \mathrm{~Hz})$ connected to a multichannel acquisition system. Selected geophones are likely suitable for the recording of seismic events but have limited low-frequency capability depending on their sensitivity $(44 \mathrm{~V} / \mathrm{m} / \mathrm{s}$ for our instrumentation) that has to be properly evaluated. The first two geophones were placed on sheltered areas of the high walls of the cliff, at a height of about $50 \mathrm{~m}$ below the top yard, on the south-eastern (ST1) and northern (ST2) side of the unstable volume. The other two stations (ST3 and ST4) were located in shallow manholes accessible from the panoramic square, with ST3 on top of the unstable volume and ST4 supposed to be outside the prone-to-fall part of the cliff (reference station). The network was planned to operate with both a continuous mode (at $250-\mathrm{Hz}$ sampling frequency) and a trigger recording (at $1-\mathrm{kHz}$ sampling frequency) based on a STA/LTA detection algorithm. In this work we only focus on the nearly 4200 hour-lasting continuous recordings acquired from October 2013 to August 2014.

\section{Ground motion in the horizontal plane and spectral ratios}

The spectral content of ambient seismic noise in the horizontal plane was computed from the $\mathrm{N}$ and $\mathrm{E}$ components of each station by calculating the Fourier spectra for each azimuth with an angular increment of one degree. For the prone-to-fall compartment (ST1, ST2 and ST3), polar plots exhibit clear peaks at specific orientations and frequencies. In contrast, no significant peak in amplitude and directionality were observed in the plots for the stable rock mass (ST4). In Figure 1c the azimuthal plot of ST3 (on the top of the unstable column) is shown in comparison with a simplified planar view of the main fractures affecting the site. Azimuths are displayed clockwise from $\mathrm{N}$, in the $1-10 \mathrm{~Hz}$ range (radial direction of the circle). In order to avoid the presence of frequencies related to human activity only the night recordings (from $0 \mathrm{AM}$ to $5 \mathrm{AM}$ ) have been stacked to produce the resulting spectrum. Comparing the polar plot (Fig. 1c) with the site map (Fig. 1c), the motion of the predominant vibrations appear to be oriented perpendicularly to the main discontinuities separating the unstable compartment from the intact rock mass. The first frequency peak (around $3 \mathrm{~Hz}$ ) is mostly oriented in N-S direction. Modal analysis should be carried out in the next future to understand if this peak and the relative motion orientation are related to the presence of the open fracture (K2) or are the results of the topographical amplification at the top of the high E-W elongated cliff. The mean direction of the second peak $(5.5 \mathrm{~Hz})$ is $\mathrm{N} 50$, perpendicular to the direction of the $\mathrm{K} 4$ system.

The spectral ratios between the horizontal and vertical components of each station (H/V method) and between the same components of the stations placed in the potentially unstable sector and the reference station (ST4) were then computed. In Figure 2 an example of the obtained results for the $\mathrm{H} / \mathrm{V}$ ratios on ST3 (at the top of the unstable column) is reported. The Probability Density Function of the ratio between the horizontal and the vertical Fourier spectra (Fig. 2a) exhibits a first clear peak at $3 \mathrm{~Hz}$, followed by a second lower one at around $5.5 \mathrm{~Hz}$. Especially for the $3-\mathrm{Hz}$ peak, the evolution of spectral ratios with time (Fig. 2b) suggests a slow fluctuation from $2.8 \mathrm{~Hz}$ to $3.1 \mathrm{~Hz}$ during the monitored period.

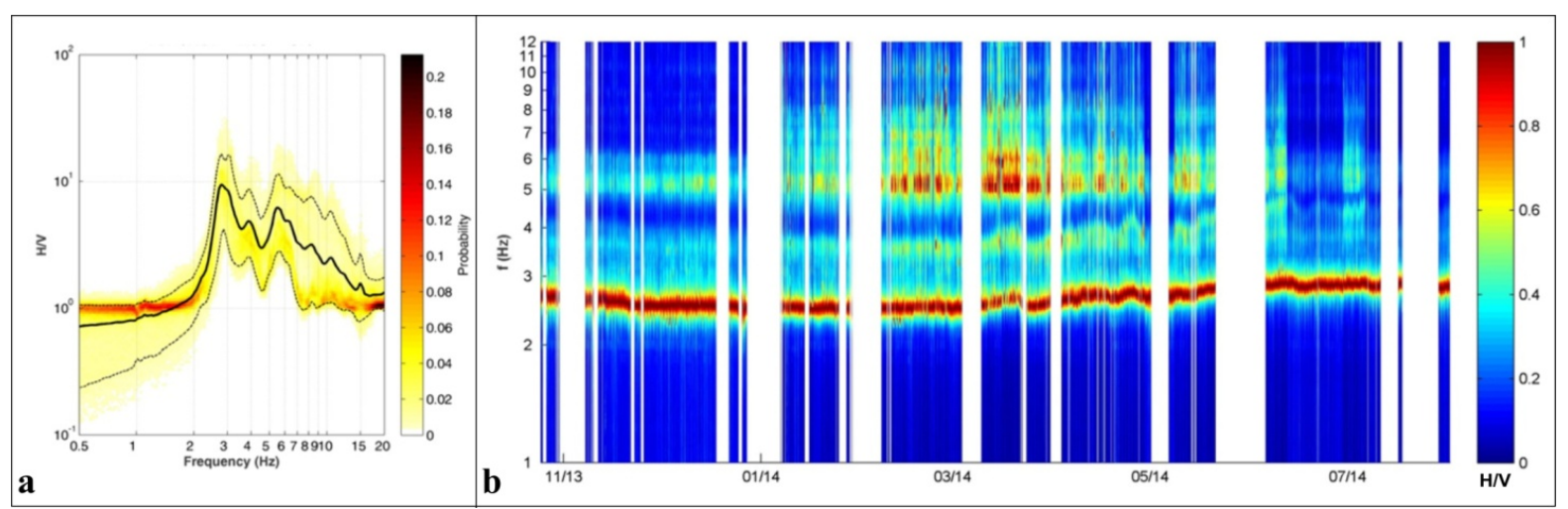

Figure 2 (a) Probability Density Function of the computed H/V spectral ratios for ST3. (b) Fluctuation of the H3/V3 spectral ratio with time; each spectrum is normalized to its maximum value. 


\section{Noise cross-correlation}

In order to monitor the variations of the seismic properties inside the rock mass the cross-correlation between the recordings of all the couples of sensors over the whole monitored period was computed. Analyses were focused in the 2 to $20 \mathrm{~Hz}$ frequency band, which roughly corresponds to a progressively reducing penetration depth of seismic waves.

Before computing the correlation, the data of each station were prepared following the same preprocessing procedure. The first processing step was the spectral whitening of the recordings in the required frequency range. This procedure is fundamental for the normalization of the frequency content of the data and works dividing each frequency by its absolute value, thus ensuring that all the frequencies in the studied bandwidth have a similar statistical contribution. Then a clipping window with a cosine transition was applied to the studied frequency band.

Correlograms were then hourly calculated for each couple of stations and averaged to obtain 24-hour correlations, ensuring more stable correlation with time. Both hourly and daily correlograms were used, in order to focus both on short-time changes (daily variations) and on long-time fluctuations (seasonal variations). Correlograms were filtered at subsequent central frequencies from $3 \mathrm{~Hz}$ to 13 $\mathrm{Hz}$, with a $2 \mathrm{~Hz}$ bandwidth. A progressive loss in correlation between the sensors was observed when increasing the central frequency of the band. The highest correlation coefficients were obtained for the 2-to-4-Hz band, while very poor correlation was found in the frequency bands higher than $10 \mathrm{~Hz}$.

Under the assumption of a homogeneous velocity change $\mathrm{dV}$, all the waveforms recorded after the velocity change are expected to be shifted in time by a factor $\mathrm{dV} / \mathrm{V}$. To measure this relative velocity change, the stretching method (Sens-Schönfelder and Wegler, 2006) was applied. This technique consists in testing several possible changes of the factor $\mathrm{dV} / \mathrm{V}$ by resampling the correlograms in time and choosing the one which maximizes the correlation coefficient CC (Mainsant et al., 2012). The intervals [- $2 \mathrm{~s}-0.5 \mathrm{~s}]$ and $[0.5 \mathrm{~s} 2 \mathrm{~s}]$ of each correlogram were employed in the computation, thus focusing on coda waves, essentially made up of surface waves. As the vertical components of the four sensors were highly noise-affected and not correctly working over the whole period, all the computations were made on the horizontal components ( $\mathrm{E}$ and $\mathrm{N})$.

The relative phase velocity changes and values of the correlation coefficient were computed for each frequency band with reference to the mean of the analyzed correlograms. The most significant $\mathrm{dV} / \mathrm{V}$ was found in the 2-to-4-Hz band (around the resonant frequency of $3 \mathrm{~Hz}$ ) with variations up to $12 \%$ in the considered six-month period (Fig 3b). Increasing the frequency of analysis, the fluctuations of $\mathrm{dV} / \mathrm{V}$ reduced up to show no variations with time, in parallel with a decrease in the values of the correlation coefficients.

\section{Conclusions}

Both the temporal variations of the resonant frequencies, obtained from the spectral analysis, and the cross-correlation of seismic noise in the lower frequency bands suggest a reversible seasonal cycle strongly controlled by temperature fluctuations (Fig. 3). Thermal contraction of the rock mass during cold months results in a decrease of the resonant frequency, probably linked with a major opening of fractures, while a maximum in the resonant frequency is observed in summer due to fracture closing as a result of thermal expansion. No irreversible changes, resulting from damage processes in the rock mass, were detected during the monitored period.

Modal and thermal modelling of the rock slope must be carried out in the next future in order to identify the modes and the volumes related to the resonant frequencies detected at the site and to better understand the temperature control on the cliff. 


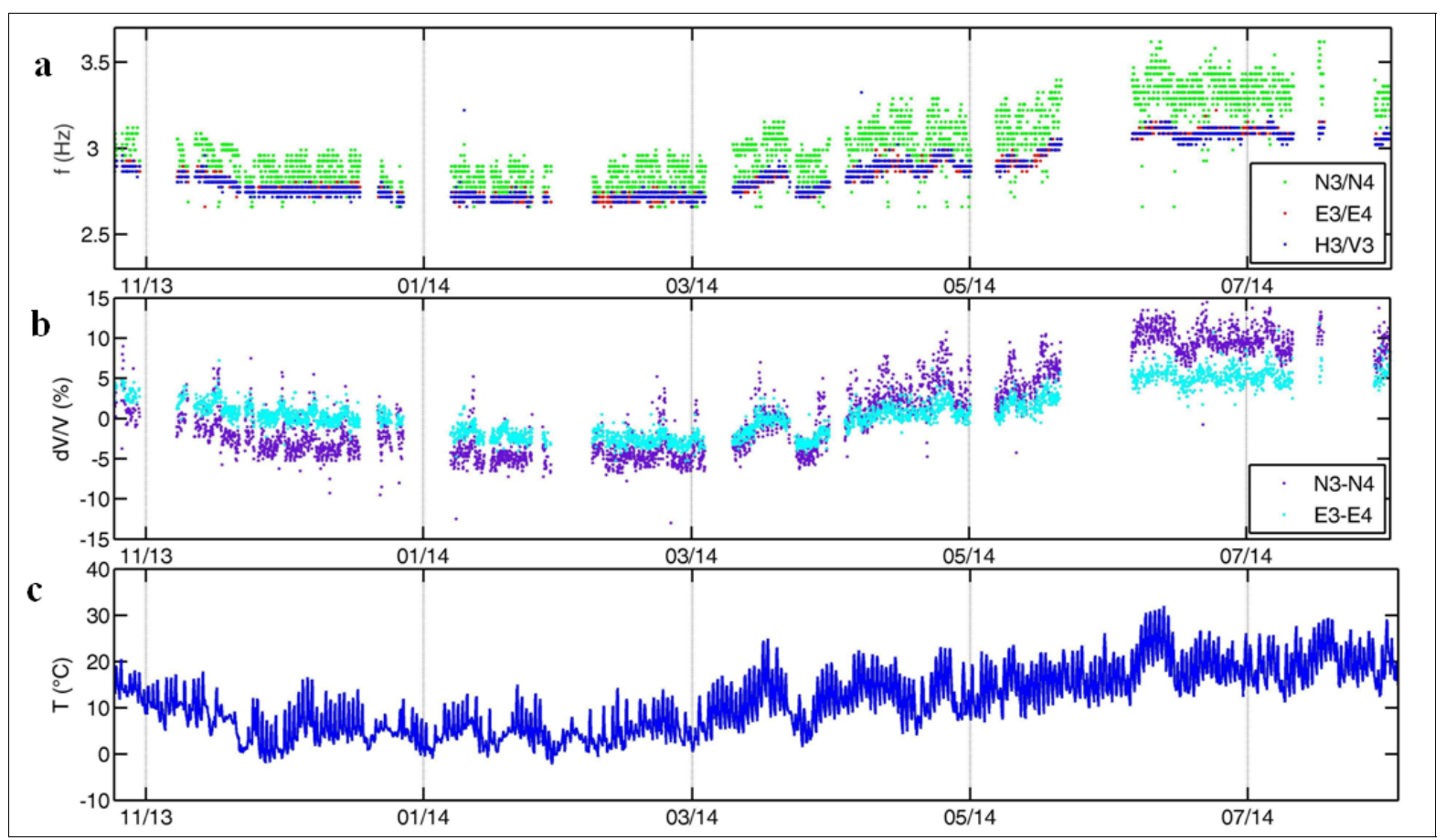

Figure 3 (a) Variations of the first resonant frequency obtained from the spectral ratios N3/N4 (in green), E3/E4 (in red) and H3/V3 (in blue). b) Cross-correlation results between ST3 and ST4 in the frequency band 2-4 $\mathrm{Hz}$ obtained from hour correlograms of the $N$ (in purple) and $E$ (in cyan) components. Only velocity variations corresponding to $C C>0.85$ are shown. c) Air Temperature $\left({ }^{\circ} \mathrm{C}\right)$ at the site during the monitored period.

\section{References}

Bottelin, P., Jongmans, D., Baillet, L., Lebourg, T., Hantz, D., Lévy, C., Le Roux, O., Cadet, H., Lorier, L., Rouiller, J.-D., Turpin, J. and Darras, L. [2013.] Spectral Analysis of Prone-to-fall Rock Compartments using Ambient Vibrations. J Environ Eng Geophys, 18, 205-217.

Burjánek, J., Moore, J.R., Yugsi Molina, F.X. and Fäh, D. [2012] Instrumental evidence of normal mode rock slope vibration. Geophys. J. Int., 188 (2), 559-569.

Lancellotta, R., Gigli, P. and Pepe, C. [1991] Relazione tecnica riguardante la caratterizzazione geologico-strutturale dell'ammasso roccioso e le condizioni di stabilità della rupe. Private communication.

Lévy, C., Baillet, L., Jongmans, D., Mourot, P. and Hantz, D. [2010] Dynamic response of the Chamousset rock column (Western Alps, France). J. Geophys. Res., 115, F04043, 13, doi: 10.1029/2009JF001606.

Mainsant, G., Larose, E., Brönnimann, C., Jongmans, D., Michoud, C. and Jaboyedoff, M. [2012] Ambient seismic noise monitoring of a clay landslide: Toward failure prediction. J. Geophys. Res., 117, F01030, 12, doi:10.1029/2011JF002159.

Moore, J.R., Gischig, V., Burjánek, J., Loew, S. and Fäh, D. [2011] Site Effects in Unstable Rock Slopes: Dynamic Behavior of the Randa Instability (Switzerland). Bull. Seism. Soc. Am., 101(6), 3110-3116.

Sens-Schönfelder, C., and Wegler, U. [2006] Passive image interferometry and seasonal variations of seismic velocities at Merapi Volcano, Indonesia. Geophys. Res. Lett., 33, L21302, doi:10.1029/2006GL027797. 